\title{
Na Primeira República, praticar espiritismo era cometer um crime indígena
}

\section{In the first Republic, the practice of Spiritism was a indigenous crime}

Adriana Gomes ${ }^{1}$

Resumo: O artigo discute a recepção do Código Penal de 1890, legislado por João Baptista Pereira no meio jurídico brasileiro, com destaque para o artigo 157, que criminalizou o espiritismo. Por meio da análise de fontes históricas, nos debruçamos em compreender os antecedentes à promulgação das leis penais da Primeira República que substituiu o Código Criminal de 1830 e os desdobramentos da não aceitabilidade entre os magistrados do país pela ausência de diálogo em sua elaboração. Na tentativa de evitar a substituição do Código Penal, Baptista Pereira reafirmou a necessidade de manutenção do código e do espiritismo permanecer uma transgressão penalcom punição carcerária por se tratar de um "crime indígena" pelo remetimento à incivilidade e à indisciplina social, tão refutados pelo recém implantado regime republicano.

Palavras-Chave: João Baptista Pereira - História do Direito - Crime Indígena Artigo 157-Espiritismo.

Abstract: The article discusses the reception of the 1890 Penal Code, legislated by João Baptista Pereira in the Brazilian legal environment, with emphasis on article 157, which criminalized spiritism. Through the analysis of historical sources, we strive to understand the background to the enactment of the penal laws of the First Republic that replaced the Criminal Code of 1830 and the consequences of nonacceptability among the country's magistrates due to the lack of dialogue in its elaboration. In an attempt to avoid replacing the Penal Code, Baptista Pereira reaffirmed the need to maintain the code and spiritualism to remain a criminal transgression with prison punishment because it is an "indigenous crime" for referring to incivility and social indiscipline, so refuted by newly implanted republican regime.

Keywords: João Baptista Pereira - History of Law - Indian Crime - Article 157 Spiritism.

\section{Introdução}

Em 1890 foi legislado por João Baptista Pereira um novo código penal para o Brasil a fim de substituir o Código Criminal de 1830 que perdurou ao longo de todo Império. Entre as novas leis penais criadas, o artigo $157^{2}$ foi considerado um dos mais

${ }^{1}$ Pós-doutora em História Social (UFRJ), Doutora em História Política (UERJ) e Professora de História SEEDUC-RJ.

${ }^{2}$ Art. 157 - Praticar o espiritismo, a magia e seus sortilégios, usar de talismãs e cartomancias, para despertar sentimentos de ódio ou amor, inculcar cura de moléstias curáveis ou incuráveis, enfim, para fascinar e subjugar a credulidade pública: Penas - de prisão celular de um a seis meses, e multa de $100 \$ 000$ a $500 \$ 000$. 


\section{SACRILEGENS

polêmicos da recente república brasileira, isto porque cerceou a liberdade religiosa e de pensamento dos cidadãos espíritas. O dispositivo penal foi inserido no Livro III referente à tranquilidade pública, no Capítulo III sobre os crimes contra a saúde pública.

Discutiremos a partir de agora como foi a substituição do Código Criminal de 1830 pelo Código Penal de 1890 legislado por João Baptista Pereira; a ausência de diálogo na implementação das novas leis penaisno meio legislativo ejurídico do país e a consequente refutação entre os pares; as tentativas de substituição da norma penal que tiveram leituras diferenciadas em relação à prática do espiritismo; e as ingerências do legislador pela não substituição das penas por ele elaboradas.

\section{A construção do controverso Código Penal de 1890}

A substituição do Código Criminal de 1830 começou a ser debatido no cenário político brasileiro após a abolição da escravatura em discussões legislativas incrementadas pelo Deputado Joaquim Nabuco (1849-1910), que em 4 de outubro de 1888 propôs a substituição da norma penal sob a argumentação de que havia a necessidade de serem suprimidas as menções aos escravos e as penalidades relacionadas à insubordinação à ordem social estabelecida.Afinal, não haveria mais razão para existir as referências à escravidão, quando a relação de trabalho no país havia se tornado livre desde a promulgação da lei 3353 de 13 de maio de 1888. Além disso, o deputado pernambucano evidenciou outra motivação para a criação de uma nova norma penal, "a necessidade de incluir-se no código disposições avulsas contidas em várias leis”, que necessitavam de regulamentações mais incisivas por meio de medidas repressivas que estivessem integradas em código com o propósito de assegurar a ordem pública, afora o aprimoramento de prescrições já existentes (ARAÚJO, 1910, p. 121-122).

Os deputados aprovaram as justificativas de Nabuco e um novo código penal começou a ser elaborado pelo professor e deputado pernambucano João Vieira de

Parágrafo $1^{\circ} \mathrm{Se}$, por influência, ou por consequência de qualquer destes meios, resultar ao paciente privação ou alteração, temporária ou permanente, das faculdades psíquicas.

Penas - de prisão celular por um ano a seis anos, e multa de $200 \$ 000$ a 500\$000.

Parágrafo $2^{\mathrm{o}}$ Em igual pena, e mais na privação de exercício da profissão por tempo igual ao da condenação, incorrerá o médico que diretamente praticar qualquer dos atos acima referidos, ou assumir a responsabilidades deles (COLEÇÃO DE LEIS DO BRASIL). 


\section{SACRILEGENS

Araújo (1844-1823), que apresentou um anteprojeto em 12 de julho de 1889 com a intenção de substituir o Código Criminal de 1830 (CANTON, 2012, p. 48; SONTAG, 2014, p. 17; ARAÚJO, 1910, p. 131).

Em suas considerações a fim de adquirir reconhecimento e aceitabilidade de seu anteprojeto, Vieira de Araújo empenhou-se em constatar que o "regime excepcional imposto [...] [pelo] Direito Criminal fere mais profundamente os sentimentos comuns de justiça e de humanidade”. Além disso, o jurista ressaltou que uma "lei viva não deve permanecer partes mortas, que representam como triste lembrança os resíduos de uma instituição condenada que já desapareceu”, em menção direta ao regime de escravidão (ARAÚJO, 1910, p. 2).

Para Vieira de Araújo, por seu texto ter as "modificações [...] necessárias" para o país, o anteprojeto atenderia às imprescindibilidades do "governo do rei", visto que deferia às demandas da sociedade por contemplar as "modificações que entender necessárias" para o ordenamento penal de forma a responder às exigências da nova estrutura social do Brasil (ARAÚJO, 1910, p. 3).

Entretanto, para ser implementado pelo governo imperial, o anteprojeto teria que ser apresentado a uma comissão de pareceristas que assenhoreariam suas apreciações favoráveis ou desfavoráveis ao texto do deputado-jurista. A comissão de pareceristas foi formada por Cândido José Maria de Oliveira (1845-1919), Antônio José Rodrigues Torres Neto (1840-1904), Visconde de Assis Martins (1839-1903) presidente da comissão - e pelo Conselheiro João Baptista Pereira (1835-1899) futuro legislador do primeiro Código Penal Republicano (ARAÚJO, 1910, p. 130).

No preâmbulo do anteprojeto entregue para análise dos pareceristas em julho de 1889, o professor da Faculdade de Direito do Recife nos evidenciou a exigência de Joaquim Nabuco para a inclusão de numerosos regulamentos administrativos instituídos como lei após a elaboração do Código Criminal de 1830, quehaviam sido criados mediante as demandas e necessidades de organização e manutenção da ordem no seio da sociedade(ARAÚJO, 1910, p. 4).

Todavia, Vieira de Araújo não hesitou em afirmar que ele havia refutado os regulamentos cuja legalidade era contenciosa e sujeita a polêmicas. A sua proposta era furtar-se de criar leis que "se pode questionar na execução, com prejuízo da autoridade e eficácia da lei”, isto é, transformar em artigos do código penal situações que tornassem a "jurisprudência caótica". O preterimento por determinados regulamentos se dariacomo medida cautelar para evitar problemas nos tribunais, pois 
os juízes se depararam com questões polêmicas a serem julgadas por conta de regulamentos insustentáveis seja pela incompatibilidade com leis criadas anteriormente ou por leis posteriores. Os processos acabariam em indeferimento (ARAÚJO, 1910, p. 4).

Assim posto, mesmo não fazendo qualquer referência específicas aos regulamentos considerados por ele ineficazes em sua atuação nos tribunais, pode-se depreender que o regulamento o qual se pretendia reorganizar o serviço sanitário no Império apresentava as características incongruentes na aplicabilidade como assegurou João Vieira de Araújo. O Decreto no 9554 de 3 de fevereiro de 1886 em seu capítulo IV dedicou-se em estipular normas para o exercício da medicina, da farmácia, da obstetrícia e da arte dentária, entretanto, não conseguiu inibir a prática ilegal da medicina pelos não habilitados academicamente, assim como a prescrição e o aviamento de remédios de qualquer natureza por curandeiros e espíritas curadores. $\mathrm{Na}$ realidade, a punição aqueles que exerciam a medicina ilegalmente não era uma incumbência fácil de ser cumprida, mesmo com um regulamento bastante claro sobre a quem deveria caber à atribuição da arte de curar: os médicos habilitados academicamente (COLEÇÃO DE LEIS DO BRASIL).

A questão que trazemos à discussão é que para João Vieira de Araújo, asregulamentações sobre o monopólio do exercício da medicinae situações relacionadas à saúde pública não foram consideradas relevantes ao ponto de serem elaborados dispositivos no código penal que a protegesse dessas práticas.

A desconsideração de Vieira de Araújo aos problemas relacionados à saúde pública, ao exercício ilegal da medicina e, por conseguinte, à prática do espiritismo na arte de curar não passaram despercebidas pelos pareceristas do anteprojeto. Eles desqualificaram a norma penal criada pelo professor por diferentes motivos, entre eles, a refutação de regulamentos que existiam e não podiam ser ignorados no Código Penal como o Decreto no 9554 . Outrossim, o procedimento de não inserir disposições penais que estavam estabelecidas em diversos regulamentos elaborados após a criação do Código Criminal de 1830, infringia uma das diretrizes estipuladas no projeto de Joaquim Nabuco de 4 de outubro de 1888, que pretendia reunir os regulamentos esparsos criados após a instituição da norma penal vigente.

Com base nesses fundamentos, a comissão considerou o anteprojeto aquém das necessidades da sociedade brasileira, por compreender que João Vieira de Araújo teria se limitado a realizar a supressão de questões relacionadas "ao elemento 
escravo" e omitido das leis penais uma série de regulamentos que deveriam ter força de lei, motivado por um processo de seleção pessoal em que o autor teria escolhido determinados decretos como viáveis de serem inseridos no Código Penal em detrimento de outros(ARAÚJO, 1910, p. 129).

Segundo a comissão, a alegação das dificuldades em se reprimir determinados crimes nos tribunais não poderia ser argumento para excluí-los no "corpo de direito". Os pareceristas compreenderam que os regulamentos deveriam ter força de lei e deveriam ser cumpridos sem qualquer tipo de sujeição à instabilidade, ainda mais em se tratando de crimes graves. Para eles o país necessitava de um Código Penal que fosserevisionista e não uma edição com atualizações que contemplassem somente a nova relação de trabalho do Brasil. Eles entendiam que as demandas exigidas deveriam ser adequadas a uma legislação penal que salvaguardasse a ordem e, com isso, pudesse inserir a nação como uma "civilização adiantada" e, para tanto, esta deveria ser "mais repressiva, mais previdente e mais aperfeiçoada" (ARAÚJO, 1910, p. 129).

Nas considerações finais na desaprovação do anteprojeto de João Vieira de Araújo, os pareceristas pontuaram as questões emergenciais que deveriam ser contempladas no novo código penal do país a fim de "acudir a imperiosos reclames sociais" em favor "da família". Consideraram que as punições às infrações deveriam ser determinantes, pois a sociedade brasileira estaria "ameaçada pela vagabundagem que cresce todos os dias nas cidades e no campo", que tornavam todos reféns de "ciladas à boa fé" por permitirem a exploração da "confiança alheia e a credulidade pública”(ARAÚJO, 1910, p. 129-130).

Com a rejeição do projeto de Vieira de Araújo, a revisão do código penal brasileiro coube ao magistrado Baptista Pereira. O trabalho do jurisconsulto não foi contínuo, em meio as suas elaborações o país mudou de regime político e, momentaneamente, as suas atividades foram interrompidas. Mas, Manoel Ferraz de Campos Sales (1845-1913), Ministro da Justiça do Governo Provisório, lhe renovou o compromisso de reformar as leis penais do país (CANTON, 2012, p. 49).

A comissão verificadora do projeto de Baptista Pereira foi nomeada e presidida pelo próprio ministro Campos Sales, que dispôs da colaboração dos seguintes outros integrantes: José Júlio de Albuquerque Barros - Barão de Sobral - (1841-1893), Francisco de Paula Belfort Duarte (1841-1913), Antônio Luiz dos Santos Werneck (1858-1914) e o próprio autor, João Baptista Pereira, que ao realizar esclarecimentos 
sobre o seu projeto mencionou que o mesmo foi aprovado "na sua quase totalidade, pois muito poucas foram as alterações que sofreu, sem falar nas emendas de mera redação" (PEREIRA, 1898, p. 266).

Assim, com pouquíssimas modificações realizadas pelos membros da comissão, o projeto de norma penal submetido por Baptista Pereira foi recepcionado pelos verificadores e se instituiu como o Código Penal dos Estados Unidos do Brasil por meio do Decreto $\mathrm{n}^{0} 847$ de 11 de outubro de 1890 . Isto é, a norma penal da Primeira República foi estabelecida com apenas doze dias após a primeira reunião da comissão sem que houvesse de fato uma discussão profícua entre os verificadores pelo escasso decurso de tempo e, sobretudo, pela privação de interesse para que houvesse desdobramentos da discussão em âmbito parlamentar e entre os pares (CANTON, 2012, p. 49; SONTAG, 2014, p. 173; BATISTA, 2011, p. 445).

A escolha de Baptista Pereira para ser o autor do Código Penal da República nos revelou uma conveniente inalterabilidade da política do país com a mudança de regime: a mesma pessoa que legislaria o novo código penal do Império deu prosseguimento ao seu trabalho em um novo regime de governo. Apesar Brasil ter se tornado uma ResPublica (coisa pública), a proposta era assegurar a ordem social estabelecida a fim de que os segmentos sociais mais favorecidos pudessem promover a manutenção de seus privilégios, sem ter o risco de passarem por significativas modificações. Para tanto, as punibilidades às infrações e a inibição à criminalidade e ao que compreendiam como sendo crimes deveriam ser estabelecidas. Era imprescindível manter sob controle uma sociedade tensionada pela desigualdade e diversidade cultural que, em possíveis tentativas de 'ajustes', poderia proporcionar consequências imprevisíveis à organização social existente no país.

Além disso, outro ponto que devemos ressaltar foi a rapidez na aprovação do Código Penal. Não ocorreram discussões entre os magistrados acerca dos dispositivos deliberados por Baptista Pereira. O governo da recente república brasileira tinha pressa em promulgar as leis punitivas aos cidadãos que acabaram por contribuir para a organização de um governo com características acentuadamente autoritárias.

Por isso houve empenho para a elaboração das leis penais antes da Constituição. A ocorrência dessa especificidade no ordenamento jurídico brasileiro, como afirmou Hédio da Silva Júnior (1999, p. 30), mostrou como o governo republicano primeiro voltou às ruas atenções na obediência da ordem, para depois o 


\section{SACRILEGENS

legislativo se ocupar com o, mero detalhe,da ordem a ser estabelecida na Carta Magna.

Assim posto, nos confere envidar como chave interpretativa para o entendimento desse momento histórico a emergência das culturas políticas autoritárias presentes no transcurso da História do Brasil. O autoritarismo pode ser identificado ao longo de nossa trajetória por meio de atitudes, de construções e de usos de determinados conceitos, que mesmo em diferentes intertextualidades, as suas inferências reaparecem ou acentuam-se com adequação à prática política do momento.

A indubitabilidade de considerarmos o autoritarismo como uma das culturas políticas do Brasil podem ser asseguradas nas medidas autoritárias evidenciadas ao longo da legitimação do novo regime que promoveram uma série de dinâmicas de ordem excludente para a maioria da população a fim de manter os privilégios de uma minoria que, por certo, era a proposta de projeto político para o país desde a implementação da República. Desse modo, cabe-nos ressaltar que em meio às circunstâncias em que se revelam problemas de ordem avultada e mediante as relevantes crises históricas tornam-se comuns as reaparições ou as evidenciações de culturas políticas, que na mudança do regime brasileiro a ocasião não foi díspar e o autoritarismo destacou-se.

A apreensão que fazemos de culturas políticas vai ao encontro às percepções do francês Serge Berstein (1998, p. 350-351; p. 362). As suas ponderações nos possibilitou assimilar a análise de um processo histórico tendo as 'culturas políticas' como fundamentação teórica, uma vez que o seu entendimento nos propiciou depreender a identidade dos indivíduos de uma sociedade por intermédio de elementos que os mantém em estreita relação uns com os outros, que pode ser identificado em discursos codificados, argumentações, palavras-chave, fórmulas repetitivas, ritos e símbolos, gestos, representação visual e comportamentos que revelam significância na organização política do Estado.

Mesmo sendo um fenômeno individual, na medida em que são interiorizados pelos indivíduos, as culturas políticas tornam-se, sobremaneira, um fenômeno coletivo produzido por grupos inteiros de uma mesma geração que vivenciaram e partilharam experiências análogas que, por sua vez, as gerações subsequentes também compartilharão os mesmos comportamentos associativos diante de novos acontecimentos. Nesse bojo, podemos pensar em culturas políticas como uma visão 


\section{SACRILEGENS

comum que, por meio de uma leitura partilhada do passado e de uma perspectiva similar de futuro, nos impressiona em comportamentos e ações na esfera política (BERSTEIN, 1998, p. 354-356).

Em vista disso, podemos sustentar que as pressuposições sobre os desdobramentos da política brasileira que resultaram na instituição do Código Penal de 1890 foi uma das contingências das culturas políticas autoritárias do Brasil, que nos conferiu em ações, representações e comportamentos que se irrompem em nossa História desde o período colonial.E decorrem pelos anos com maior ou menor significância por transcursão de aprazadas dinâmicas políticasque, no advento da mudança de regime e nos anos que transcorreram a Primeira República, a eminência do autoritarismo foi percebível em diversas experiências políticas.

A indispensabilidade do novo regime em estabelecer regras e punibilidade aos brasileirosque de alguma maneira não se enquadravam às diretrizes de engendramento da ordem pública que se pretendia para o país, foi espelhado no Código Penal de 1890 que acabou por ser instituído com uma série de equívocos, nos quais se destaca a sua diligente instituição, sem a requisição de muitos critérios e sem discussões profícuas, que promoveram o seu prestígio à bancarrota por diversos juízes.

Segundo Sontag (2014, p. 174; p. 207), tanto para os magistrados simpatizantes e seguidores do classicismo jurídico, como o próprio Baptista Pereira, quanto para os seus oponentes teóricos que se apropriavam das assertivas da Escola Positiva, o Código Penalda república não foi considerado qualificado. Os motivos da discordância foram distintos pelo diferenciado no olhar teórico, mas em comum ficou a percepção que as leis penais de 1890 estariamaquém do Código Criminal de 1830, considerado ultrapassado pelo próprio tempo, porémconseguia angariar apreço entre profissionais do Direito.

Entre as inúmeras afirmações contráriasao código de Baptista Pereira destacamos as considerações dos bacharéis em Direito João da Costa Lima Drummond (1865-1914) e João Pereira de Monteiro (1845-1904). Lima Drummond expôs em muitos discursos ingerências favoráveis à essencialidade de se realizar reformasna lei penal republicana para que houvesse receptividade junto à sociedade e nos próprios meios jurídicos. A sua convicção na necessidade de serem realizadas mudanças ficou copiosamente registrada em um de seus impressos ao ressaltar que o jurista o qual colaborasse em elaborar tamanha "magnitude", além de trabalhar em 
favor do Direito realizaria, sobretudo, um "ato de patriotismo" ao Brasil (DRUMMOND, 1898, p. 5).

Já o jurista João Pereira de Monteiro mostrou o seu descontentamento com a norma penal quando expressou as suas apreensões ao meio jurídico mediante a significativa frase - "o peior de todos os códigos conhecidos" -, em sua avaliação sem rodeios. João Monteiro proferiu a frase em meio a umdiscurso que, sem imprecisão, nos mostrou o desprezo que dispensava ao código penal do país (NORONHA, 2009, p. 59-61).

Um dos argumentos contraproducentes sobre o Código Penal de 1890 que reverberou quase de forma uníssona entre os pares de Baptista Pereira - a rapidez que as leis penais foram escritas - foi relativizada nas análises do contemporâneo professor de Direito Nilo Batista (2011, p. 445-449). Ele considerou o tempo de escrita da norma penal satisfatório, tendo em vista que ela foi somente uma revisão da anterior com a inserção de regulamentos independentes. O escopo era o Código Criminal de 1830. Além disso, o trabalho já havia sido instaurado no regime monárquico, assim, o tempo da produção do código não foi o problema, o que desserviu a norma de Baptista Pereira foi a ausência de diálogo com as outras esferas de poder e seus pares.

Na ocasião da mudança do regime no país a parte geral da nova norma já estaria pronta e, ao ser confirmado como legislador do Código Penal republicano por Campos Sales, o codificador só deu prosseguimento aos seus trabalhos já iniciados, cujo processo transcorreu por mais três meses. A rapidez na aplicabilidade das leis penais, que o cerne de discussões não deve ter atribuída apenas ao Baptista Pereira. A responsabilidade foi de toda comissão verificadora que aprovou o projeto no intervalo de doze dias(BATISTA, 2011, p. 445; PEREIRA, 1898, p. 258).

Durante a vigência do Código Penal de 1890, ao longo da Primeira República, as modificações ao texto original foram muitas. Diversas leis extravagantes foram criadas, porque seus autores consideraram que o legislador da norma não teria se debruçado da forma adequada em determinados pontos, principalmente naqueles referentes à tranquilidade pública. Assim, com o argumento de inibir o crime, as leis extravagantes tiveram o propósito de cercear ainda mais as liberdades individuais daqueles considerados os óbices da sociedade, cuja recepção da norma penal era considerada ineficiente, tais como: imigrantes indesejáveis, anarquistas, prostitutas, capoeiras, cáftens, espíritas, entre outros. Por certo que, as medidas estavam indo ao 


\section{SACRILEGENS

encontro à política autoritária da Primeira República em que a manutenção da ordem era condição sinequa non do novo regime de governo, mesmo que para o propósito fosse avultado o cerceamento das liberdades (BATISTA, 2011, p. 442).

Nesse bojo, os espíritas se viram mais uma vez coagidos por meio do Regulamento Sanitário - Decreto $n^{0}$ 5.156, de 8 de Março de 1904 - no qual em seu artigo $251^{3}$, a norma específica aos serviços sanitários a cargo da União cerceava algumas práxis dos adeptos ao espiritismo (COLEÇÃO DE LEIS DO BRASIL).

Todavia, vale ressaltar que muitas críticas às inoperâncias da norma republicana em contraposição do Código Criminal de 1830 eram improcedentes, na medida em que muitos expedientes considerados eficazes no código do império eram os mesmos deliberados na norma penal da República, mas a crítica só verificava ausência de operacionalidade no código de Baptista Pereira. O contemporâneo jurista Nilo Batista (2011, p. 443-446) atribuiu à aversão e o desprestígio da norma penal ao insucesso no combate aos problemas relacionados à ordem social e à tranquilidade pública.

Assim, a contrariedade constrangida ao Código Penal de 1890 não era meramente técnica, eram muito mais por razões de estrutura política que, asseguradamente, oportunizaram a criação as inúmeras leis extravagantes que pretendiam assegurar a manutenção da ordem e da tranquilidade pública em meio à coexistência de anteprojetos que litigavam substituir a primeira norma penal republicana como os elaborados por João Vieira de Araújo e Galdino Siqueira, que nos debruçaremos a analisar.

\section{As tentativas de substituição do Código Penal de 1890 e as considerações em relação ao artigo 157}

Em 1893, somente três anos após a promulgação das leis penais da Primeira República, João Vieira de Araújo apresentou outro projeto de substituição, que ficou totalmente revisto em 1897.0 projeto passou inúmerasapreciações críticas, inclusive

3Art. 251 - Os médicos, farmacêuticos, dentistas e parteiras que cometerem repetidos erros de ofício serão privados do exercício da profissão, por um a seis meses, além das penalidades em que puderem incidir no art. 297 do Código Penal.

Parágrafo único. Os que praticarem o espiritismo, a magia, ou anunciarem a cura de moléstias incuráveis, incorrerão nas penas do art. 157 do Código Penal, além da privação do exercício da profissão por tempo igual ao da condenação, se forem médicos, farmacêuticos, dentistas ou parteiras (COLEÇÃO DE LEIS DO BRASIL). 


\section{SACRILEGENS

dos professores das Faculdades de Direito de São Paulo e de Recife. Os profissionais do Direito realizaram uma série de considerações favoráveis e desfavoráveis a fim de contribuir na elaboração da postulante mudança das leis penais. Entretanto, mesmo aprovado pela Câmara dos Deputados em 1897, o substitutivo da legislação penal não foi à frente e perfez-se em neutralidade no ano de 1899 quando foi remetido ao senado, por onde se desvaneceu a proposta pela descontinuidade das discussões, mesmo em meio às supostas certezas de Araújoquanto à aprovação de seu projeto (ARAÚJO, 2004a, p. 3; BATISTA, 2011, p. 456; SIQUEIRA, 1913, p. 6-7).

João Vieira de Araújo foi um dos muitos juristas que ao construir críticas ao código de Baptista Pereira enaltecia o Código Criminal de 1830, que ele próprio havia criado um anteprojeto de substituição que fora desconsiderado, como vimos anteriormente. O professor pernambucano afirmava que "todos sabem que o código de 1830 é em seu contexto o projeto do deputado Bernardo Pereira de Vasconcellos, que como temos dito e repetido, com intuição genial, consagrou nele ideias hoje reputadas oportunas pela escola moderna na ciência criminal” (ARAÚJO, 2004b, p. 32), ou ainda na afirmação o código de 1830 seria excelente pelas "preciosas originalidades" que continha (ARAÚJO, 2004a, p. 8).

As justificativas de Vieira de Araújo ao não assentimento ao Código Penal de 1890 e a apresentação de um projeto de substituição iam ao encontro do discurso de seus pares juristas: melhorá-lo a fim de preencher as lacunas deixadas por Baptista Pereira. Para tanto, o jurista considerou essencial aproveitar o que ambos os códigos anteriores poderiam oferecer de forma a contribuir para a consecução de um novo código penal (ARAÚJO, 1896, p. 8).

Segundo Vieira de Araújo, seu projeto teve considerações bastante engrandecedoras para o campo jurídico brasileiro, assim como para o campo internacional. Uma série de revistas estrangeiras como a Revista Penale e Archivos di psichiatria, scieng e penali ed antropologia criminale divulgaram as suas proposições de substituição do código republicano. Contudo, o jurista tinha a percepção que o seu projeto estaria longe da "reforma radical" que a norma penal deveria passar, apesar de apresentar significativos avanços em relação ao Código Criminal de 1830, ao código de Baptista Pereira e de seu próprio anteprojeto de 1889 (ARAÚJO, 1895, p. 43).

Em suas referências em relação à criminalização do espiritismo, João Vieira de Araújo nos evidenciou percepções diferenciadas as de Baptista Pereira. A primeira 


\section{SACRILEGENS

crítica sub-repticiamente pontuada referiu-se à organização do Código Penal de 1890, sobretudo a inclusão de um capítulo voltado exclusivamente à saúde pública que, em seu olhar, pareceu-se mais com uma compilação de regulamentos do que a normatização de leis penais, que o tornou confuso. Por isso, ele queria estabelecer um Código Penal que tirasse "todas as dúvidas que [pudessem] embaraçar o juiz diante das invenções da rabulice”. O projeto de Araújo teria favorecidoemrelevância à dedicação às "figuras essenciais" aostemas imprescindíveis em detrimento de temas que ele considerava dispensável para estarem nas leis penais de um país (ARAÚJO, 2004a, p. 194).

Assim posto, o jurista considerou inadmissível que uma norma penal no apagar das luzes do século XIX pudesse fazer qualquer referência à feitiçaria e afins e, mais agravante, criar dispositivos penais diretamente demandados aos feiticeiros. Para ele a atitude de Baptista Pereiraacarretou uma série de injunções falaciosas ao promover uma ordem de penalidades que não teriam receptividade epara que houvesse "homenagem a nossa cultura jurídica", as referidas legislações deveriam ser refutadas (ARAÚJO, 2004a, p. 195).

Entre as considerações de Vieira de Araújo adversas às percepções de Baptista Pereira estavam as relacionadas ao crime de praticar feitiçaria, a prática do espiritismo e afinscomo crença religiosa. Entretanto, ao emitir a sua interpretação em relação ao livre exercício da medicina, a liberdade no exercício do ofício de curar, o posicionamento de Araújo ia ao encontro às percepções de Baptista Pereira. Mesmo sendo conhecedor da salvaguarda à liberdade profissional instituída na Carta Magna de 1891, que poderia impossibilitar a receptividade de sua interpretação nos tribunais de justiça.

Os artigos 156 e 158 do Código Penal de 1890 previam punições para quem exercesse a medicina e artes afins, assim como para aqueles que prescrevessem medicamentos sem a habilitação acadêmica exigida. Entretanto, a Constituição de 1891 por meio de seu artigo 72 parágrafo 24, concedia a garantia de livre exercício de qualquer profissão moral, intelectual e industrial sem a exigência de capacitação por meio de graduação. Dessa maneira, a lei maior do país consentia que as profissões pudessem ser exercidas por qualquer pessoa, inclusive a medicina, sem que as exigências hábeis de capacitação do ofício fossem prescritas. No entanto, o jurista pernambucano não condescendia com a permissividade da Constituição e, dessa forma, revelava que práticas realizadas por espíritas relacionadas à cura deveriam, 
realmente, ser elididas por meio de penalidades (ARAÚJO, 2004a, p. 197; COLEÇÃO DE LEIS DO BRASIL).

Para evidenciar com clareza o seu entendimento sobre essa antinomia nas normas brasileiras, Vieira de Araújo debruçou-se em dar um exemplo ao seu leitor a fim de esclarecer com persuasão a necessidade de se restringir as liberdades profissionais estabelecidas na Constituição de 1891. Ele sugeriu que fosse permitido a qualquer um o direito de instalar uma usina insalubre de explosivos na Rua do Ouvidor, centro da Capital Federal. A hipótese seria tão absurda por sua periculosidade, que o jurista correlacionou a circunstância à liberdade de qualquer um em exercer a advocacia, a arte de curar, na mesma condição que qualquer um poderia ser um industrial de explosivos no centro do Rio de Janeiro. Assim sendo, mesmo com a asseguração do artigo 72 parágrafo 24 da Constituição dos Estados Unidos do Brasil em assentir a liberdade profissional, este dispositivo não poderia ser interpretado como uma "doutrina absoluta que dispense a prova de capacidade especial para o exercício de qualquer profissão" (ARAÚJO, 2004a, p. 197-198).

Em apreciação ao artigo 157, cuja referência à criminalização do espiritismo era categoricamente expressa, Vieira de Araújo perfez o seu parecermediante o posicionamento teórico de quatro juízes que julgaram processos de réus que sofreram a ação penal por terem praticado o espiritismo, cujos argumentos sentenciais o persuadiram. Os juízes apreciadas foram: Gabriel Ferreira (1848-1905), SubProcurador no Distrito Federal; Miranda Ribeiro (1854-1907); Lima Drummond (1865-1914); e Francisco José Viveiros de Castro (1862-1906), a quem o professor Araújo evidenciou com mais relevância as suas proposições por compreender que os pressupostos do magistrado seriam os mais procedentes (ARAÚJO, 2004a, p. 198).

Gabriel Ferreira descortinou ao João Vieira de Araújo que "a simples prática do espiritismo não constitui crime" por se tratar de uma manifestação da liberdade de consciência garantida pela Constituição do país, portanto o artigo 157 seria improcedente. Já os juízes Miranda Ribeiro e Lima Drummond revelaram que a ambição e a ganância de algumas pessoas sobre outras pessoas por meio de embustes, de qualquer natureza, deveriam ser consideradas falsificações, como se houvesse usurpação de um nome ou de uma firma social com o propósito de iludir o comprador. Destarte, pelo Código Penal de 1890 o criminoso deveria ser enquadrado nos artigos 353 e 355 relacionados à falsificação e ao estelionato, e não por 


\section{SACRILEGENS

intermédio de um artigo na qual a referência era a uma confissão religiosa (ARAÚJO, 2004a, p. 198-199).

Em referência ao Viveiros de Castro, o jurista pernambucano se apropriou de suas considerações, sobretudo as relacionadas às apreensões na qual as práxis do espiritismo poderia viabilizar o cometimento de crimes contra a personalidade e a propriedade. Sobre as transgressões contra a personalidade, Vieira de Araújo notabilizou que esta violação somente ocorreria em situações nas quais o "chefe da seita espírita” promovesse algum tipo de dano à saúde ou que pudesse induzir as pessoas à morte mediante práticas de ritos provenientes de cultos sob o pretexto de serem religiosos. Quanto ao crime contra a propriedade, o pernambucano se apropriou das percepções de Viveiros de Castro ao sustentar que o delito somente adviria se houvessem fraudes e encenações que pudessem suscitar esperança e ou temor nas pessoas por meio de artifícios de algum suposto "acontecimento quimérico". Dessa maneira, a prática do espiritismo seria somente um pretexto para os delituosos praticarem o crime com evidências de estelionato (ARAÚJO, 2004a, p. 198-199).

Ainda em apropriação de interpretações de Viveiros de Castro em relação aos feiticeiros, Vieira de Araújo afirmou que ser 'feiticeiro' não poderia ser considerado uma ocupação profissional, porque não poderia subsistir qualquer argumentação para a garantia do acautelamento sob a legitimação na Constituição de 1891, pela liberdade de exercício profissional, uma vez que 'feiticeiro' não se encontraria em qualquer relação de profissões exequíveis (ARAÚJO, 2004a, p. 198-199).

Nessa ordem, Vieira de Araújo não interpretou o espiritismo um crime por si mesmo, mas não negligenciou que alguns indivíduos mal-intencionados poderiam se sustentar por meio de práxis do espiritismo para promoverem dissimulaçõesa fim de enganar e explorar outros indivíduos por suas ações. Nesses casos, os praticantes desse simulado espiritismo poderiam e deveriam ser julgados e passíveis de punições pelos delitos cometidos contra a personalidade e ou contra a propriedade (ARAÚJO, 2004a, p. 198-199).

Da mesma maneira que Vieira de Araújo propôs um projeto de substituição ao Código Penal de 189o, o paulista Galdino Siqueira(1872-1961) também submeteu um anteprojeto 4 de revisão à norma penal republicana em 1911 com a consubstanciação

$4 \mathrm{O}$ anteprojeto de Galdino Siqueira sequer foi analisado pelo Poder Legislativo (BATISTA, 2011, p. 456). 


\section{SACRILEGENS

ocorrida em 1913 por meio da autorização do Ministro da Justiça Esmeraldino Bandeira (1865-1928). O procedimento nos revelou a indubitável inquietude quanto à insuficiência de receptividade às leis penais de Baptista Pereira.

Ante as diversas controvérsias sobre a criação do artigo 157, Galdino Siqueira também se debruçou em evidenciar as suas percepções sobre o dispositivo penal, assim como, nos expôs seu entendimento sobre a prática do espiritismo. Siqueira compreendeu em seu projeto que fraudes e embustes ocorridos por meio de subterfúgios de práxis espíritas deveriam ser enquadrados nos crimes de estelionato. Em vista disso, os seus comentários sobre os artigos 156, 157 e 158 do Código Penal de 1890 foram analisados no capítulo que se referia à falsificação. Aquele que se auto intitulasse curandeiro e cometesse fraude e iludisse a boa-fé de outrem, responderia pelos atos delituosos que praticasse, como qualquer outro profissional que cometesse irregularidades e ludibriasse as pessoas. Quanto especificamente ao artigo 157, o legislador considerou-o uma "figura delituosa" na norma penal do país, uma vez que seria incapaz de "subsistir em face da Constituição Republicana", pois o espiritismo era uma religião em que a suas práxis estariam no "ramo das ciências ocultas cultivadas em todos os países" e que, por isso, deveria ter o seu exercício assegurado, tendo em vista que constitucionalmente o artigo 72 e seus respectivos parágrafos assentiam a sua regularidade. Nesse sentido, para Galdino Siqueira era inaceitável que um código penal pudesse dispor de um dispositivo com a atribuição aferida em punir a "feitiçaria e seus processos" (SIQUEIRA, 1913, p. 125).

Assim posto, podemos constatar que os anteprojetos criados a fim de substituir o Código Penal de 1890 não condescenderam com as percepções do legislador Baptista Pereira em relação à legitimidade do artigo 157. Tanto o projeto de Vieira de Araújo quanto o projeto de Galdino Siqueira foram ao encontro às percepções dos agentes sociais que postularam a revisão do artigo ou à sua supressão. Apesar das interpretações dos legisladores dos projetos substitutivos terem ficado no meio do caminho, houve reconhecimento entre os magistrados que seria um equívoco a criação de um dispositivo penal que punisse o espiritismo de uma forma generalizada no sentido literal da forma como foi produzido o artigo 157. 


\section{SACRILEGENS

\section{João Baptista Pereira sai em defesa de seu Código Penal}

Apenas em 1898 que João Baptista Pereira se pronunciou sobre as suas apropriações e suas motivações para a criação do Código Penal Republicano. Podemos considerar tardio o tempo de réplica, uma vez que as críticas de seus pares eram sucessivas e austeras. Além disso, tornam-se mais extemporâneas quando comparamos a réplica proferida pelo jurisconsulto às manifestações adversas promovidas pela Federação Espírita Brasileira5 diante da promulgação do artigo 157, que mereceram as suas apreciações em menos de dois meses da instituição das leis penais, por intermédio de publicações realizadas no Jornal do Commercio.

Todavia, antes de discutirmos a defesa direta de Baptista Pereira ao seu código penal, como mencionamos, vale ressaltar que, sub-repticiamente, o legislador da norma de 1890, sob a chancela do Instituto da Ordem dos Advogados Brasileiros, atuou como relator do Parecer sobre o Projecto de Reforma do Código Penal, em que uma comissão formada por ele, João da Costa Lima Drummond (1865-1914), José Cândido de Albuquerque Mello Mattos (1865-1924) e João Martins de Carvalho Mourão (1872-1951) deram as suas apreciações ao projeto de substituição do código penal proposto por João Vieira de Araújo (INSTITUTO DA ORDEM DOS ADVOGADOS BRAZILEIROS, 1897, p. 25).

A comissão do Instituto da Ordem dos Advogados Brasileiros questionou muito a legitimidade de reforma do Código Penal de 1890, cujo escopo atenderia às necessidades sociais de maneira tão diferenciada quanto ao código vigente. Foi afirmado queo projeto de reforma de Vieira de Araújo não resistiria a um confrontamento direto com o Código de Baptista Pereira que, por certo, "não teria de que vexar-se no confronto". No parecer, foi afirmado que não bastava criticar a norma hodierna por conter equívocos de doutrina e imperfeições na redação, era necessário conseguir escrever uma norma mais assertiva. Ademais, para a comissão ninguém poderia se "considerar autorizado a condenar em absoluto um código penal [...] mesmo entre os que fazem a glória no nosso tempo, se conhece que tenha

5 Para compreender mais sobre as discussões entre a Federação Espírita Brasileira e João Baptista Pereira, ler o artigo: GOMES, Adriana. O enfrentamento pelas penas dos tinteiros: a dissensão nos impressos cariocas sobre a liberdade religiosa dos espíritas. Revista do Arquivo Geral da cidade do Rio de Janeiro. Rio de Janeiro: n. 4, 2018, p. 263-296. 
escapado a essa lei da contingência humana" (INSTITUTO DA ORDEM DOS ADVOGADOS BRAZILEIROS, 1897, p. 25).

A comissão teceu a opinião de que se o "código penal vigente não é perfeito, os projetos apresentados em substituição dele são imperfeitíssimos". Por isso, o projeto de Vieira de Araújo não poderia ser convertido em lei pelas inabilidades em atender a diversas demandas que foram pontuadas e, entre elas, aquelas que não contemplariam as necessidades sociais como a imprevidência nas demandas da saúde pública do Brasil por condescender às práticas do espiritismo no país (INSTITUTO DA ORDEM DOS ADVOGADOS BRAZILEIROS, 1897, p. 25).

Os membros da comissão do Instituto da Ordem dos Advogados Brasileiros compreenderam como um acinte Vieira de Araújo dar mais importância à repreensão ao exercício do "ofício de capoeira" do que ao exercício do ofício de "curandeiro", uma vez que os dois casos seriam "crimes indígenas", isto é, transgressões inatas do que decorreriam da incivilidade e da indisciplina social, que tanto eram refutados pelo regime republicano, por primar pela manutenção da ordem, sobretudo na Capital Federal. Por serem "dois casos de endemia" na sociedade, as transgressões precisavam dispor de atenção em equidade, como fora realizado no código de 1890. Eram crimes que revelavam a "idiossincrasia moral do nosso meio", portanto deveriam ser coibidos vigorosamente, sem a possibilidade de subterfúgios para a não punibilidade (INSTITUTO DA ORDEM DOS ADVOGADOS BRAZILEIROS, 1897, p. 8).

Para a comissão era necessário neutralizar impetuosamente a atuação dos curandeiros, que por meio de "máscaras" especulavam a credulidade das pessoas e fomentavam superstições sob o pretexto de curar mediante prescrições terapêuticas "vindos de além-túmulo", que ainda promoviam dinâmicas impressionistas aos indivíduos por intermédio de supostas comunicações oriundas do mundo invisível, assim como, com as adivinhações, com as práticas de cartomancia, os usos de talismãs, em que os "feiticeiros" empenhavam-se em fascinar e em subjugar a credulidade pública, proporcionando à sociedade a perturbação de seu "sossego e a paz das famílias e ameaçando a saúde e a vida da população". Em vista disso, para os pareceristas do Instituto da Ordem dos Advogados Brasileiros o projeto de Vieira de Araújo não atenderia às necessidades de proteção à sociedade, pelo contrário abriria precedentes para que o "crime indígena" pudesse ocorrer sem a punibilidade que lhe 
era necessária, isto é, a prisão carcerária (INSTITUTO DA ORDEM DOS ADVOGADOS BRAZILEIROS, 1897, p. 8-9; ).

Conquanto, como analisamos anteriormente, o olhar de Vieira de Araújo não era permissivo com a prática do espiritismo fraudulento, assim como a qualquer outro embuste. Sua condescendência era pela liberdade religiosa e de consciência, da mesma forma como compreendeu Galdino Siqueira. O professor pernambucano não reconhecia a necessidade de se ocupar com a punibilidade de 'feiticeiros' em um código penal no limiar do século XX. As análises da comissão do Instituto da Ordem dos Advogados Brasileiros foram muito mais defensivas ao Código Penal de 1890, do que realmente a realização de um parecer imparcial. Certamente, a presença do próprio legislador na comissão não poderia tornar a apreciação totalmente isenta de intervenções para a causa própria.

Outra situação decorrida que nos pode conferir a ausência de imparcialidade no parecer da comissão pela participação de Baptista Pereira, seria o assentimento de Lima Drummond às pressuposições sobre o "crime indígena" e a total intolerância a prática do espiritismo. O próprio jurista havia sido mencionado por Vieira de Araújo como uma de suas referências a fim de elaborar considerações sobre o artigo 157 do código penal. Lima Drummond compreendia que era procedente a existência de embustes por meio de práxis espíritas em que estes deveriam ser analisados judicialmente como estelionato da mesma maneira que qualquer outra ação que iludisse, dissimulasse e afrontasse a boa-fé da pessoa. Assim,nos tribunais de justiça a percepção de Lima Drummond destoava do parecer do Instituto da Ordem dos Advogados Brasileiros.

Como os membros da comissão eram conhecedores das inúmeras críticas ao Código Penal de 1890, inclusive algumas elaboradas por Lima Drummond, trataram de atribuir as possíveis lacunas da norma penal às circunstâncias históricas na qual ocorrera a promulgação. Como o Governo Provisório em 1890 concentrava todos os poderes em suas mãos, o código foi aprovado de forma sumária, com a justificativa de viabilizar a facilitação de seus "intuitos e o fazia chegar mais depressa ao seu fim". Por isso, não ocorreram discussões parlamentares e, tampouco, houvediálogo entre os profissionais do campo jurídico que atuariam em Faculdades, Institutos e até cientistas de direito criminal que tivessem influência nas áreas de conhecimento da antropologia, medicina legal e psiquiatria (INSTITUTO DA ORDEM DOS ADVOGADOS BRAZILEIROS, 1897, p. 3-4). 


\section{SACRILEGENS

Como as críticas ao Código Penal de 1890 eram numerosas e Baptista Pereira ainda não havia se pronunciado diretamente aos seus pares sobre os seus propósitos e métodos empregados na construção da norma penal, o jurisconsulto decidiu esclarecer as indagações e revelar as suas motivações, os seus pressupostos e finalidades ao redigir o código penal da república.O impresso escolhido por Baptista Pereira para publicar suas Notas Históricas sobre a codificação penal do país foi a Revista Jurisprudência em 1898. Como Baptista Pereira demorou certo tempo para se pronunciar sobre o código penal, ele considerou oportuno justificar a sua postergada atitude sob a alegação de que não existia tempo algum estipulado a ocorrência de explicações aos juristas e à sociedade. Por isso, somente o fez quando compreendeu necessidade e por considerar a circunstância oportuna e conveniente, tendo em vista que na ocasião estava em discussão no meio jurídico a substituição do Código Penal. Dessa forma, o codificador das leis penais se manifestou com a intenção de "confrontar o que temos com as novidades com que se nos quer felicitar" as revisões propostas no projeto que estava em discussão em diferentes espaços jurídicos do país (PEREIRA, 1898, p. 376).

Por certo, a principal motivação de Baptista Pereira em se pronunciar era tentar salvaguardar o seu Código Penal que estava sob a ameaça de substituição por meio do projeto impetrado por Vieira de Araújo. Para tanto, o legislador debruçou-se, sobremaneira, em referendar os avanços de sua norma penal em relação à norma anterior.

Baptista Pereira iniciou as suas considerações investindo críticas implacáveis ao Código Criminal de 1830, que era apreciado por muitos de seus pares como uma norma penal mais razoável do que o código republicano. Entretanto, ele considerou o apreço ao código do Império "porque o que tínhamos antes era péssimo, era simplesmente detestável”. Não havia como comparar o Código Criminal com a legislação oriunda de Portugal, isto é, qualquer legislação criada em terras brasileiras para que os brasileiros se submetessem seria muito melhor do que normas estipuladas pela metrópole portuguesa. Destarte, pelo código de 1890 ter substituído outro código criado em solo brasileiro, envidava a possibilidade de comparações e, em seu entendimento, em razão disso decorria-se algumas críticas contraproducentes (PEREIRA, 1898, p. 3).

Em relação à rapidez com que o seu projeto foi aprovado, Baptista Pereira comentou que a proposta inicial para a autoria do código penal, ainda no Império, era 


\section{SACRILEGENS

que na finalização de seus trabalhos haveria a apresentação do código ao Conselho de Estado que realizaria as "observações, alterações e emendas, que fossem indicadas e sugeridas pelos censores”. Conquanto, com a mudança de regime político as análises realizadas pelos especialistas foram suprimidas em decorrência de questões inerentes ao contexto histórico, nesse decurso, as alterações realizadas foram mínimas e o código foi "adotado na sua quase totalidade [...] com emendas de mera redação" sem que houvesse desdobramento de discussões entre os juristas (PEREIRA, 1898, p. 177266).

Em favorecimento próprio, Baptista Pereira realizou intervenções defensivas ao seu código penal a fim de evidenciar as progressões garantidas. Entre os avanços, o jurisconsulto destacou a unicidade da pena para a prisão carcerária, por ele considerada como "intimidativa, repressiva e penitenciária, da qual foi a chave da abóboda de todo o sistema repressivo”. Destacou entre as conquistas asseguradas no Código Penal, aquelas que não tinham qualquer menção no Código Criminal de 1830 e que se faziam necessárias para a manutenção da ordem, uma vez que proporcionariam a "segurança da honra e da honestidade das famílias", pelo seu código não subsistir à "frouxidão de [...] regime punitivo, que era antes um estímulo, do que um corretivo" (PEREIRA, 1898, p. 226-229).

Suas referências aos supostos avanços nas leis penaisnos referendou com uma consideração interessantíssima com a discriminação das "novas figuras delituosas introduzidas no campo da legislação penal”, consideradas por Baptista Pereira expressivas conquistas na área do Direito, entre elas a criminalização de práticas que relacionavam-se à saúde pública, entre eles o artigo 157 que criminaliza a prática do espiritismo e os artigos 156 e 158 que poderiam criminalizar espíritas por algumas de suas práxis relacionadas à cura (PEREIRA, 1898, p. 226-231).

Sendo assim, asseveramos que Baptista Pereira mesmo após oito anos da instituição do artigo 157 e com o conhecimento das diversas manifestações adversas à criação do substitutivo penal, com argumentações em diferentes acepções, o jurisconsulto não realizou qualquer reconsideração em sua diligência em criminalizar o espiritismo. Na realidade, o codificador da norma penal se ensoberbecia por tê-lo criado e ainda considerá-lo, junto aos outros artigos mencionados, uma progressão na legislação do país. 


\section{SACRILEGENS

\section{Considerações Finais}

Consideramos que a leitura do espiritismo como um 'crime indígena' por romper com a tranquilidade pública corroborava com o discurso sobre a sociedade brasileiranos anos finais do século XIX, principalmente na área da medicina social. Este campo do saber ganhou destaque na Primeira República por ser engendradora daconstrução de um 'país civilizado'. Dessa maneira, à medicina social foi conferida a autoridade de ser a controladora com plenos recursos para ser refreadora dos pressupostos excessos nas relações sociais e comportamentais que denotassem 'incivilidade' em qualquer uma de suas evidenciações, inclusive no entendimento de fé e de religiosidade.

Nesse prisma, os problemas de organização social, demográfico e até de ordem econômica, perpassariam pelos expedientes de saneamento e de higienização, e se tornariam os principais entretecedores para o êxito do projeto de redefinição do Brasil, sobretudo da Capital Federal, que deveria sobrepujar os supostos valores, hábitos e costumes das saneadas e higienizadas cidades europeias que, pelas suas dimensões cosmopolitas e 'civilizadas', deveriam ser paradigmas a serem transpassados para o país, cujas dimensões seriam forjadas com a mediação do controle da saúde pública.

A medicina social promoveria um novo tipo de conhecimento sobre o homem em que o seu arbítrio era oportunizar a viabilidade do projeto de ordem para que a sociedade pudesse cumprir os deveres estabelecidos em cooperação às decisões que se apresentavam, a fim de se preservar o que supostamente seria de todos em um meio normatizado. A medicina impediria apropagação dos excessos ao favorecer a expectativa de civilização que, destarte, era incompatível com coexistência de procedimentos terapêuticos por meio de práticas curandeiras e espíritas, pejorativamente consideradas charlatanices.

Os procedimentos de cura fora do esfera dos profissionais academicamente formados refutariam o controle da saúde da população por intermédio da ciência, que era imprescindívelpara o exercício profissional dos médicos, os mediadores do pretenso progresso civilizatório que, efetivamente, tencionavam controlar os corpos descomedidos e enfermos para transmudá-los em corpos impassíveis e sadios.

Nessa ordem, a atuação de espíritas na arte de curar não se adequaria ao país que se desejava compor no limiar da República, com o agravante de que uma das 


\section{SACRILEGENS

principais especificidades da Doutrina Espírita, a 'relação entre o mundo visível com o mundo invisível', não ser um princípio fundamental somente aos seguidores do espiritismo. As religiões de matriz africana também manifestavam este tipo de 'relação entre mundos', com outros princípios elementares. Porém, a mediunidade e os seus desdobramentos poderiam ser compreendidos com algumas similitudes entre as religiosidades sobreditas.

Assim, em um país que construía a sua República com o olhar defronte para a Europa e dando-lhes as costas para a sua própria composição cultural e racial, poderia se pressupor que não caberia à legitimação de práxis religiosas que reportassem aquilo que se tentava contrapor.

Embora o espiritismo tivesse a sua origem na França e muitos de seus adeptos fossem intelectuais, profissionais liberais e indivíduos influentes na política brasileira, a 'relação entre os mundos' por meio da mediunidade, reportava os seus procedimentos aos costumes, as religiosidades e as tradições culturais que não faziam parte de um projeto vislumbrado para o Brasil.

$\mathrm{Na}$ realidade, os "crimes indígenas" - capoeira e espiritismo - que Baptista Pereira argumentou intensamente no Parecer sobre o projecto de reforma do Código Penal e em suasNotas Históricas como necessários a serem combatidos no Brasil, era a refutação de resistentes legados de indígenas, africanos e afro-brasileiros de tendência transgressora por imputarem intranquilidade à manutenção da ordem pública por não estarem de acordo com os princípios preconizados de civilidade.

\section{Fontes Impressas}

ARAÚJO, João Vieira.Código Penal commentado theorica e pratica. Rio de Janeiro: Laemmert\&C. Editora, 1896.

. Nova Edição do Código Criminal Brasileiro de 1830: anteprojeto elaborado em 1889. Rio de Janeiro: Imprensa Nacional, 1910. fac-similar, 2004 a.

O Código Penal Interpretado I. Brasília: Senado Federal - STJ, Ed. . O Código Penal Interpretado II. Brasília: Senado Federal - STJ, Ed. fac-similar, $2004 \mathrm{~b}$. 


\section{SACRILEGENS \\ Revista Discente do Programa de

CAMARGO, Romeu do Amaral. O protestantismo e o espiritismo à luz do evangelho: resposta ao Sr. Dr. Carlos de Laet e ao Sr. Prof. Revmo. Othoniel Motta. São Paulo: Irmãos Ferraz, 1928.

DRUMMOND, João da Costa Lima. Estudos de Direito Criminal. Rio de Janeiro: Laemmert\& C., 1898.

PEREIRA. Baptista João. Notas Históricas - O código Penal de 1890. In: Revista de Jurisprudência. Rio de Janeiro: Janeiro-Abril, ano II, 1898.

SIQUEIRA, Galdino. Projecto de Codigo Penal Brazileiro. Rio de Janeiro: Graphs. Do Jornal do Brasil.

\section{Fontes disponíveis na Web}

COLEÇÃO DE LEIS DO BRASIL. Código Penal de 189o. Disponível em: http://legis.senado.gov.br/legislacao/ListaPublicacoes.action?id=66049. Acesso em 13 de agosto de 2016.

COLEÇÃO DE LEIS DO BRASIL. Constituição da República dos Estados Unidos do Brasil de 1891. Disponível em:

http://www.planalto.gov.br/ccivil_03/Constituicao/Constituicao91.htm. Acesso em 26 de agosto de 2016.

\section{Referências Bibliográficas}

BATISTA, Nilo. Direito Penal Brasileiro I. Rio de Janeiro: Revan, 2003.

BERSTEIN, Serge. A cultura política.In:RIOUX, Jean Pierre; SIRINELLI, JeanFrançois (orgs.). Para uma história cultural. Lisboa: Editorial Estampa, p. 349-363, 1998.

CANTON FILHO, Fábio Romeu. Bem Jurídico Penal. Rio de Janeiro: Elsevier, 2012.

CHALHOUB, Sidney. Trabalho, lar e botequim. São Paulo: Editora Unicamp, 2001.

GOMES, Adriana. O enfrentamento pelas penas dos tinteiros: a dissensão nos impressos cariocas sobre a liberdade religiosa dos espíritas. Revista do Arquivo Geral da cidade do Rio de Janeiro. Rio de Janeiro: n. 4, 2018, p. 262-296.

LUDEÑA, Gustavo. Dos Experiencias Místicas de loNuminoso. Numen: revista de estudos e pesquisa de religião. Juiz de Fora: v. 4, n. 1, p. 87-118.

MACHADO, Roberto; LOUREIRO, Angélica; LUZ, Rogério; MURICY, Kátia. Danação da norma: medicina social e constituição da psiquiatria no Brasil. Rio de Janeiro: Graal, 1978.

NORONHA, Edgard Magalhães. Direito Penal I. São Paulo: Riddel, 2009. 
RODRIGUES, Antônio Edmilson Martins. Em algum lugar do passado:cultura e história na cidade do Rio de Janeiro. In: AZEVEDO, André Nunes (Org.). Capital e capitalidade. Rio de Janeiro: UERJ, p. 11-43, 2002.

SILVA JR., Hédio. Direito Penal em preto e branco. In: Revista Brasileira de Ciências Criminais. São Paulo, ano 7, n. 27, p. 327-338, 1999.

SONTAG, Ricardo. Código Criminológico: ciência jurídica e codificação penal no Brasil: 1888-1899. Rio de Janeiro: Revan, 2014.

Recebido em: 06/05/2020

Aceito em: $17 / 06 / 2020$ 